\title{
Second language influence on first language motion event encoding and categorization in Spanish-speaking children learning L2 English
}

Article

Accepted Version

Aveledo, F. and Athanasopoulos, P. (2016) Second language influence on first language motion event encoding and categorization in Spanish-speaking children learning L2 English. International Journal of Bilingualism, 20 (4). pp. 403420. ISSN 1756-6878 doi: https://doi.org/10.1177/1367006915609235 Available at https://centaur.reading.ac.uk/43898/

It is advisable to refer to the publisher's version if you intend to cite from the work. See Guidance on citing.

To link to this article DOI: http://dx.doi.org/10.1177/1367006915609235

Publisher: Sage

All outputs in CentAUR are protected by Intellectual Property Rights law, including copyright law. Copyright and IPR is retained by the creators or other copyright holders. Terms and conditions for use of this material are defined in the End User Agreement. 


\section{www.reading.ac.uk/centaur}

\section{CentAUR}

Central Archive at the University of Reading

Reading's research outputs online 
Aveledo, Fraibet \& Athanasopoulos, Panos (in press). . International Journal of Bilingualism. To be published in the Special Issue "Cross-linguistic aspects in child L2 acquisition".

Article title: Second language influence on first language motion event encoding and categorization in Spanish-speaking children learning L2 English

\begin{abstract}
Studies show cross-linguistic differences in motion event encoding, such that English speakers preferentially encode manner of motion more than Spanish speakers, who preferentially encode path of motion. Focusing on native Spanish speaking children (aged 5;00-9;00) learning L2 English, we studied path and manner verb preferences during descriptions of motion stimuli, and tested the linguistic relativity hypothesis by investigating categorization preferences in a non-verbal similarity judgement task of motion clip triads. Results revealed L2 influence on L1 motion event encoding, such that bilinguals used more manner verbs and fewer path verbs in their L1, under the influence of English. We found no effects of linguistic structure on non-verbal similarity judgements, and demonstrate for the first time effects of L2 on L1 lexicalization in child L2 learners in the domain of motion events. This pattern of verbal behaviour supports theories of bilingual semantic representation that postulate a merged lexico-semantic system in early bilinguals.
\end{abstract}

\title{
Keywords
}


Motion events, thinking-for-speaking, manner and path encoding, linguistic relativity, categorisation

\section{Introduction}

Since Whorf stated that language can bias our worldview (Whorf, 1956), his hypothesis, the linguistic relativity (LR) principle, has experienced substantial theoretical changes, intense debate, and empirical attention in a range of disciplines. The findings from recent studies have caused the hypothesis to evolve and diversify into more fine-grained proposals (see Wolff \& Holmes, 2010, for a detailed overview). Modern approaches to LR thus aim to explore how and under which conditions crosslinguistic differences in the semantic partitioning of reality may give rise to crosslinguistic differences in thought. A basic tenet in this line of inquiry is the operationalization of 'thought' as non-verbal behaviour, instantiated typically as a range of different cognitive processes, such as reasoning, classification, and categorical perception (Lucy, 1997). The consensus that arises from recent empirical studies is that language transitorily fine-tunes, rather than permanently shapes, essential elements of human cognition, such as categorisation and perception (Athanasopoulos \& Bylund, 2013; Regier \& Kay, 2009).

An alternative framework for probing the relationship between language and thought has been put forward. Slobin's (1987, 1996a) thinking-for-speaking (TFS) hypothesis postulates that speakers of different languages think differently while mentally preparing content for speech. Specifically, speakers attend to and verbalise those aspects of reality that are readily encodable in their language. The crucial difference between LR and TFS is that the former focuses on effects of linguistic structure on non-verbal behaviour, while the latter focuses on effects of linguistic structure on speech planning and information structure. 
Each language has its own set of grammatical options for encoding any message and speakers are prone to express their messages according to these sets of options (for empirical evidence see Sebastian \& Slobin, 1994; Slobin, 1996b; Slobin \& Hoiting, 1994).

The present study aims to investigate LR and TFS in the context of bilingualism, by exploring whether acquiring an L2 early in life may influence the process of non-linguistic categorization and the lexicalisation patterns of motion events in Spanish-speaking children, learning English. The main question here is whether L1-specific cognitive categorisation and verbal encoding are impervious to L2 influence, or whether restructuring can occur under the influence of an L2.

Given the substantial cross-linguistic diversity in the semantic portioning of reality, and the correlation of this diversity with different cognitive dispositions in monolingual populations, recent studies have investigated LR and TFS through the bilingualism lens. As far as LR is concerned, it has been shown that cognitive categorisation may be impervious to L2 influence in intermediate L2 users (see Athanasopoulos, 2006 in the domain of grammatical number) or late bilinguals (see Boroditsky, Schmidt, \& Phillips, 2003 in the grammatical gender domain). Cognitive categorization may be influenced by the L2 once an advanced level of proficiency has been reached (see Athanasopoulos \& Kasai's 2008 study on number and objects), in early bilinguals (see Boroditsky, 2001 on time conception), and as a function of Grosjean's (2001) theory of language mode (see Kersten, Meissner, Lechuga, Schwartz, Albrechtsen, \& Iglesias, 2010 in the domain of motion events).

In TFS studies, it was shown that verbal encoding patterns established in an L1 are particularly resistant to restructuring under the influence of an L2 with different encoding patterns (see Malt \& Sloman, 2003 in a study of object naming). However, L2 influences 
L1 encoding patterns under certain conditions, such as increasing L2 proficiency (see Bylund \& Jarvis' 2011 study on grammatical aspect and endpoint encoding), in early bilinguals (Ameel, Storms, Malt \& Sloman, 2005 in the domain of object naming), and as a function of the age of onset of bilingualism (see Bylund, 2009; Hohenstein, Eisenberg \& Naigles, 2006 on motion event encoding).

This paper contributes to this recent wealth of studies in two ways. Firstly, we explore effects of L2 on L1 motion event encoding in child L2 learners. To date, studies in monolingual L1 acquisition show that language-specific encoding patterns emerge early in L1 development (Choi \& Bowerman, 1991), but continue to develop until at least 9 years of age (Slobin, 1996b). The majority of studies exploring L2 effects on L1 motion event encoding make inferences about early bilingualism based on adult participants who started learning the L2 at a young age (e.g. Hohenstein et al., 2006; Bylund, 2009). Therefore, it is unclear whether L2 influences L1 encoding patterns relatively early in child L2 acquisition, or whether such effects can only be observed later in life. Secondly, we test whether linguistic structure affects non-verbal motion event categorisation in child L2 learners. To date, such cross-linguistic categorisation studies have focused exclusively on monolingual children (e.g. Papafragou \& Selimis, 2010).

We aim to fill those gaps in our knowledge by conducting a systematic investigation of TFS and LR in Spanish and English monolingual children, and in Spanish-speaking children with L2 English.

\section{Motion Events in Spanish and English}

Dynamic motion events are differently encoded across languages. Languages could encode path of motion in the verb or in a satellite element (Talmy, 1985). English is a 
satellite-framed language because it typically encodes path in a satellite position through a prepositional phrase or particle. English could also be called a 'manner language' because the main verb usually expresses manner of motion (i.e. the way a figure moves, see example (1)); native speakers of English rarely omit manner information and English boasts a rich vocabulary of manner verbs (Slobin 1996b). Spanish is a verb-framed language: the verb tends to express path of motion (i.e. the trajectory the figure takes), while manner is encoded in adverbial phrases or not expressed at all. Slobin and colleagues consistently found these tendencies in verbal production tasks (Sebastián \& Slobin, 1994; Slobin \& Hoiting, 1994; Slobin, 1996a); see example (2).

(1) (English): The boy ran [vrb. manner] out [prep. path] of the building.

(2) (Spanish): El niño salió [vrb. path] del edificio corriendo [adv. phrs. manner]. 'the boy exited the building running'

Studies support that English is a typical manner language, however there is evidence to suggest that Spanish speakers also prefer to encode manner in verbs under some circumstances. For example, Slobin and Hoiting (1994), based on the Aske's (1989) study, elaborated the boundary-crossing constraint. The researchers suggest that when a figure crosses a boundary (e.g. a change of location), Spanish speakers have to produce a path verb in order to convey the boundary-crossing information. When no boundary is crossed (e.g. a figure moving within a building), Spanish speakers can use manner verbs. In manner languages, such information is conveyed through the use of manner verbs in both boundary-crossing and non-boundary crossing events, simply by changing, for example, the relevant preposition (e.g. 'He ran into the building' vs. 'He ran in the building'). 
Experimental studies (Naigles et al., 1998; Feist, Rojo \& Cifuentes, 2007) support the hypothesis that Spanish speakers tend to use more manner verbs to describe non-boundary crossing events and more path verbs when describing boundary-crossing events. The present study considers this observation by analysing Spanish speakers' and bilinguals' performance on boundary-crossing and non-boundary-crossing events.

\section{Motion event construal in $\mathrm{L} 1$ development}

The motion event linguistic system does not seem to be fully developed before the age of 7 or 9 years-old (Slobin, 1996b; Hohenstein, 2005), so the question arises as to when cross-linguistic differences in TFS and LR, if any, may become observable. As far as we know, very few studies have assessed these hypotheses developmentally. Papafragou, Massey, and Gleitman (2002) analysed how language affects memory and categorisation in English and Greek (a path language, like Spanish). They compared monolingual Greek and English-speaking children (aged 5 and 10). Results from a linguistic description task showed clear cross-linguistic differences in TFS even in the younger groups. Greek speakers used more path verbs while their English-speaking peers preferred manner verbs. However, in the non-verbal motion categorisation task (where participants matched a manner or path alternate to a target), no significant differences between language groups were found, leading the authors to reject LR.

Papafragou et al.'s (2002) study utilised static pictures instead of dynamic stimuli (e.g. video clips), giving rise to the possibility that the critical elements of the motion event (manner and path) were not accurately presented (Kersten et al., 2010). This criticism was addressed in Papafragou and Selimis (2010), where the authors used dynamic motion events. Results from Greek and English-speaking children around 5 years of age showed 
the expected TFS differences (English children produced more manner verbs than Greek children), and a difference in triads matching only when the instructions contained linguistic cues that might have led participants to use their language (e.g. Look! The turtle is doing something!). When the instruction changed ( e.g. Look! Do you see the same know?), no cross-linguistic differences were observed. The authors concluded that while verbal processing of motion events is susceptible to influence from language-specific typological characteristics, language particularities do not shape non-verbal cognitive categorisation.

\section{L2 effects on L1 motion event construal}

To our knowledge, only two studies to date have looked at the effects of the L2 on the L1 in motion event construal in the domain of manner vs. path, namely Hohenstein et al. (2006) and Brown and Gullberg (2010). Both of these studies have used adult participants. Hohenstein et al. (2006) elicited video descriptions and studied bidirectional influence of L1 and L2 in native speakers of English L2 Spanish. Results showed that when describing in Spanish, bilinguals produced more manner verbs than Spanish monolinguals did; when describing in English, bilinguals produced fewer manner verbs than English monolinguals did. However, this pattern was qualified by an age of acquisition effect. The authors found an effect of L2 on L1 only in early bilinguals (their Spanish had fewer path verbs, a finding replicated in this study), while in late bilinguals they found a bidirectional effect.

In Brown and Gullberg (2010) lexicalisation patterns were studied in adult native speakers of Japanese (a path language) learning English, and in monolingual Japanese and English speakers. The results showed an effect of the L2 on the L1 even at intermediate stages of English proficiency in the bilinguals. L2 learners used a mixed strategy for path 
lexicalisation in their L1 (a typically Japanese presence of path verbs mixed with a high use of path adverbials, more typical for English).

\section{Research questions}

Against the background presented in the previous sections, this study investigates the following research questions:

i) How do Spanish-speaking and English-speaking monolingual children encode motion events? Based on previous studies, English speakers should be biased towards manner verbs in their encoding behaviour to a greater extent than Spanish speakers (and vice versa for path verbs). The aim here is to see how early in L1 development such cross-linguistic differences between English and Spanish speakers become apparent.

ii) Does acquiring a second language in childhood affect the encoding of motion events in an L1? of Spanish-English bilinguals? The aim is to test the penetrability of the L1 by the L2 in early second language development of Spanish children learning English as an L2.

iii) Does language affect non-linguistic categorization in Spanish-speaking children, English-speaking children and Spanish-English bilinguals, and if so when is this influence observed developmentally? The aim is to test LR in monolingual and L2 development. If path/manner lexicalisation effects extend beyond TFS, we expect English speakers to show a greater bias towards manner-based categorization than Spanish speakers (and vice versa for path). In bilinguals, the aim is to gauge the influence, if any, of their specific languages (L1 and L2) on cognition. 
iv) What are the motion event encoding preferences and non-verbal categorization preferences in Spanish-speaking children and S-E bilingual children when they are shown boundary-crossing paths and trajectory-paths? Following previous research (Slobin \& Hoiting, 1994), we expect to see an increased preference for path verbs with videos depicting boundary-crossing paths relative to videos showing trajectory-paths, but does this boundary-crossing constraint manifest itself differently in bilinguals, and do these preferences change over time?

\section{Method}

For addressing the research questions, two different tasks were designed: a verbal encoding (linguistic) task and a similarity judgment (non-linguistic) task. Through the linguistic task we studied encoding differences between English and Spanish by asking monolingual English-speaking children, monolingual Spanish-speaking children and children who are native speakers of Spanish, learning L2 English (henceforth, S-E bilinguals ${ }^{1}$ ) (aged 5 to 9 ) to describe videos showing motion events. S-E bilinguals described the clips in their L1 Spanish, since our aim was to explore L2 effects on L1 event description.

Through the similarity judgement task, non-verbal cognitive dispositions towards manner and path were studied. Participants watched a target video showing a motion event in which both a path component and a manner component were compounded (e.g. a man walks into a room). Immediately, participants were presented with two variants of the target video. In one, the manner was changed in relation to the target (e.g. the man crawls into the room). In the other, the path was altered in relation to the target (e.g. the man walks out of 
the room). After watching the triad, participants had to decide which of the variants was more similar to the target video.

Children were presented with the non-linguistic task before the linguistic task to avoid the influence of prior verbal encoding of the stimuli on responses in the non-linguistic task. Experiment 1: Similarity judgment task

Participants. Ninety-one children took part. However, we report results from 88 participants, since 3 children (one from each of the three groups studied) did not understand the task. Thirty-eight monolingual English-speaking children, 37 monolingual Spanishspeaking children; and 16 L1 Spanish speakers, who are also early L2 English learners (S-E bilinguals). Ages varied from 5 to 9 . All shared the same socioeconomic level (middle class) and attended primary schools in Venezuela or the UK.

Children were grouped into two age groups (see table 1). Age group 1 (AG1) comprised children from 5 to 6 years old; Age group 2 (AG2) included children from 7 to 9 years old. The rationale for making this age group division is connected to cognitive characteristics of children rather than their English knowledge. Children aged between 5;00 to 6;00 are stabilizing their myelination process and are different cognitively from 7;00 year old children or older (Nagy, Westerberg, Klingberg 2004).

We looked for children capable of performing both the verbal and the non-verbal tasks and we found that children from age 5;00 were able to understand the similarity judgment task. Hence, Children aged 5;00 were the youngest group in our study. Although 5 yearolds could seem too old for developmental studies, many investigations show that between 5 and 9 years of age motion event encoding patterns are still developing (e.g. Sebastian and Slobin, 1994). Furthermore, Lucy and Gaskins (2001), in a study comparing children and 
adult speakers of Yucatec and English, found that only 9 year-old children were similar to adults in their cognitive preference for shape or material, suggesting that effects of language on cognition (LR) are not observable until late in development.

Table 1. Age and language groups of participants

\begin{tabular}{|l|l|l|l|}
\hline \multirow{2}{*}{} & \multicolumn{2}{|l|}{ AGE-GROUPS } & Total \\
\cline { 2 - 4 } & AG 1 & AG 2 & \\
\hline English-speakers & 21 & 17 & 38 \\
\hline Spanish-speakers & 19 & 18 & 37 \\
\hline S-E learners & 6 & 10 & 16 \\
\hline Total & 46 & 45 & 91 \\
\hline
\end{tabular}

Native English speakers were born in the UK, and recruited from 5 schools in different UK cities. Each child's background was checked using a questionnaire. Additionally, we checked that children had no knowledge of any path language. Native Spanish speakers were born in Venezuela. They were recruited from two schools (in different cities) that teach English for two hours per week. In consultation with teachers, and by administering the questionnaire, we selected children with no or very little knowledge of English. Children also completed the PPVT (Peabody Picture Vocabulary Test, American version).

Bilingual speakers were recruited from a bilingual school in Venezuela where children attend courses, and are spoken to, in English. We consider these children early learners, as all of them started to learn English before the age of 3 through the medium of instruction (rather than naturalistically, they are not therefore simultaneous bilinguals). Children aged 5 to 7 attended around 8 hours of English classes a week; children from 8 to 9 had half of their lessons in English (14 hours per week). Children's English proficiency was measured by PPVT, American Version (see mean raw scores in Table 2). The PPVT measures 
receptive vocabulary and it allows us to easily compare language proficiency in children. The PPVT offers the possibility to convert raw scores obtained in the test to normalised scores provided by the PPVT (i.e. the test has been nationally standardised in USA and the scores can be compared to mental ages). Once an individual's score has been converted to the normalised score, the test provides information about the mental age equivalent of that score. For comparison purposes, we added the normalised scores of a typical monolingual English-speaking child. A raw score of 51.1 corresponds to a normalised score of a 3;07 year-old native English-speaking child (Dunn \& Dunn, 1981). The test starts from 2;06 years of age. Therefore, all Spanish speakers, except AG2 S-E bilinguals, showed the knowledge of English of a child younger than 2;06 years-old, hence the ' 0 ' cells in the table. S-E bilinguals from AG2 showed the knowledge of native English-speaking children from 3;07 to 3;09 years-old.

Table 2. PPVT mean raw scores (and standard deviations) in native Spanish speakers and their age equivalent of a normal monolingual speaker of English

\begin{tabular}{|c|c|c|c|c|}
\hline & \multicolumn{4}{|c|}{ PPVT (American version) } \\
\hline & AG1 & $\begin{array}{l}\text { Equivalent age in } \\
\text { normalised score in } \\
\text { English speakers }\end{array}$ & AG2 (SD) & $\begin{array}{l}\text { Equivalent age in } \\
\text { normalised score in } \\
\text { English speakers }\end{array}$ \\
\hline $\begin{array}{l}\text { Spanish } \\
\text { monolinguals }\end{array}$ & $6.53 \quad(6.79)$ & 0 & $18.58(8.02)$ & 0 \\
\hline S-E learners & $18.29 \quad(5.85)$ & 0 & $51.1 \quad(19.78)$ & $3 ; 07-3 ; 09$ \\
\hline
\end{tabular}

Studying children living in their L1 country, with small, daily doses of a L2, allows us to study the effects of L2 learning in isolation, without the possible confounds of cultural immersion in an L2-speaking environment (cf. Brown \& Gullberg, 2010). All children also 
performed the PPVT in their native language to confirm their vocabulary development was normal.

Materials. The materials consisted of 7 sets of 3 silent video clips of 6 seconds showing self-initiated spontaneous motion events (e.g. a man walked around a room) (as opposed to caused motion, e.g. a man bounced a ball around a room). Five more sets were designed as fillers, containing motion events that did not present the contrasts (manner and path) presented in the experimental stimuli. Each experimental triad consisted of a target video in which a person moved in a particular path and manner. Then, two variants were created. In variant 1 , the figure followed the same path as the target, in a different manner (manner change variant). In variant 2 , the figure followed the same manner as the target but a different path (path change variant). Figure 1 shows an example of a triad of videos.

Figure 1. A set of stimuli. Upper photo shows the target. Central photo shows the manner change variant. Lower photo shows the path change variant.

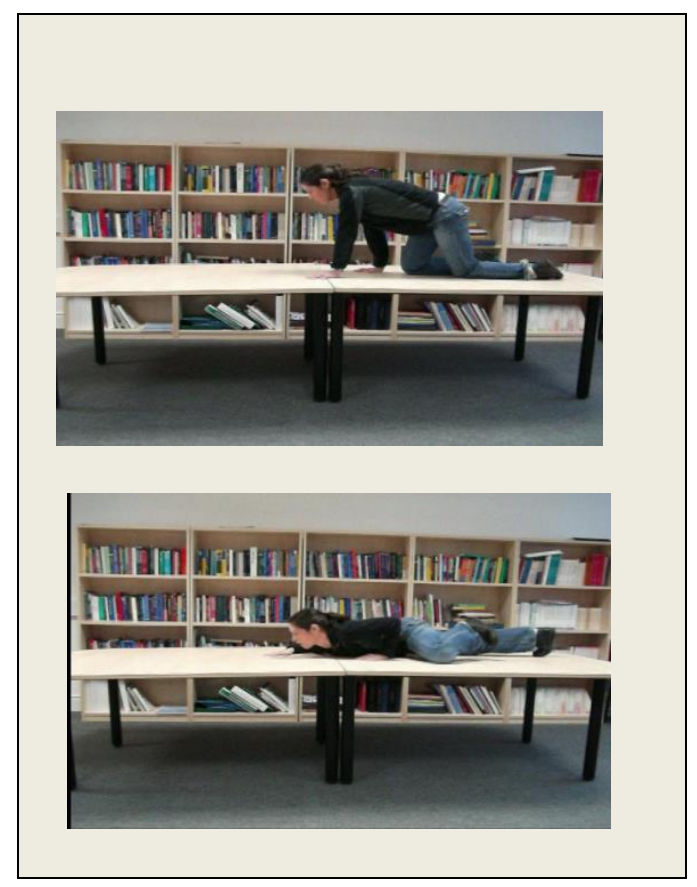




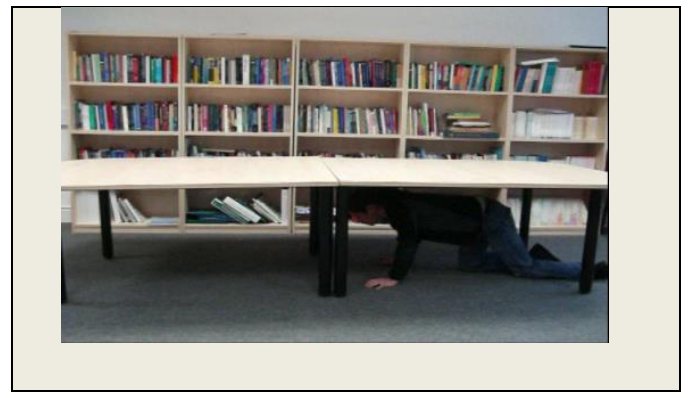

Paths involved different spatial relations (in, out, across, over, down, zigzagging, following a straight line, following a square path pattern). Following Slobin and Hoiting's (1994) hypothesis, we grouped stimuli into two different types of paths: 5 triads showed boundarycrossing paths, 2 triads showed trajectory paths. This division of stimuli seems unbalanced. However, we included more boundary-crossing path stimuli because previous studies have either used exclusively, or in the majority, such types of path (e.g. Gennari et al. ,2002; Papafragou and Selimis, 2010). We wanted to make our results as comparable as possible to those of previous studies, and the inclusion of trajectory paths was purely exploratory. On the other hand, manners involved different ways of motion. Table 3 shows the pathmanner structure of each video.

Table 3. Path-manner structure of video clips for the path vs. manner condition

\begin{tabular}{|c|c|c|c|}
\hline Target video & same path variant & $\begin{array}{l}\text { same manner } \\
\text { variant }\end{array}$ & type of event \\
\hline $\begin{array}{l}\text { 1. a woman is } \\
\text { dancing into a } \\
\text { room }\end{array}$ & ...jumping into... & ...dancing out of... & boundary-crossing \\
\hline $\begin{array}{l}\text { 2. a woman is hoping } \\
\text { into a building }\end{array}$ & $\begin{array}{l}\text {...is walking } \\
\text { into... }\end{array}$ & $\begin{array}{l}\ldots \text { is hoping out } \\
\text { of... }\end{array}$ & boundary-crossing \\
\hline $\begin{array}{l}\text { 3. a woman is } \\
\text { twirling into a gym }\end{array}$ & $\begin{array}{l}\text {...is waddling into } \\
\text { the gym }\end{array}$ & $\begin{array}{l}\text {...is twirling out } \\
\text { of... }\end{array}$ & boundary-crossing \\
\hline $\begin{array}{l}\text { 4. a man is walking } \\
\text { out of a room }\end{array}$ & $\begin{array}{l}\ldots \text { is crawling } \\
\text { out... }\end{array}$ & $\ldots$ is walking into... & boundary-crossing \\
\hline 5. a woman is jogging & ... is walking & ...is jogging out of... & boundary-crossing \\
\hline
\end{tabular}




\begin{tabular}{llll}
\hline into a room & into... & & \\
\hline $\begin{array}{l}\text { 6. } \\
\text { a woman is } \\
\text { crawling over a } \\
\text { table }\end{array}$ & $\begin{array}{l}\text {...dragging herself } \\
\text { over... }\end{array}$ & $\ldots$ is crawling under & Trajectory \\
\hline $\begin{array}{l}\text { 7. } \\
\text { a man is jumping } \\
\text { following a square } \\
\text { pattern }\end{array}$ & $\begin{array}{l}\text {...is twirling } \\
\text { following a square } \\
\text { pattern }\end{array}$ & $\begin{array}{l}\text { f..is jumping } \\
\text { following a straight } \\
\text { line pattern }\end{array}$ & Trajectory \\
\hline
\end{tabular}

Procedure. In a PowerPoint presentation, the target was shown first, followed by the two variants. The variants were shown twice, in both orders. That is, in half of the experimental videos the target was first followed by the path-change variant and then by the manner change variant; in the rest, the target was followed by the manner change variant, then by the path change variant. Thus 24 trials (14 experimental) in total were shown in a fully randomised order.

The target video was named $\mathrm{X}$ on the top of the slide, and the variants were named $\mathrm{A}$ and B. The instruction was: which video $(A$ or $B)$ do you think is more similar to $X$ ? and in Spanish ¿Qué video $(A$ o $B$ ) crees que es más parecido a $X$ ? Following the triad of videos, the screen went white, and the participant gave the answer. The task administrator pressed ENTER and the next triad appeared.

All speakers were instructed in their native language (with S-E bilinguals instructed in Spanish).

Experiment 2: Verbal encoding of motion events

Participants. The same speakers from the non-verbal similarity judgement task participated in this experiment. 
Materials. Twelve video clips of 6 seconds, each showing spontaneous motion events, were utilised. These were divided into 7 experimental stimuli and 5 fillers. The experimental videos were the target videos from the non-linguistic triads matching task (see experiment 2). Five of the 7 clips showed boundary crossing paths, 2 showed trajectorypaths ${ }^{2}$.

Procedure. Immediately after finishing the non-linguistic task, participants were given instructions for the linguistic task: "Say in few words, but in a whole sentence, what you think has happened in the video." In Spanish this was: "Di en pocas palabras, pero en una oración completa qué crees que sucedió en el video" All speakers were instructed in their native language (S-E bilinguals were instructed, and described the clips, in Spanish since our aim was to explore L2 effects on L1 event description). A researcher who was a native speaker of Spanish with high proficiency in English administered the task. The clips were fully randomised and shown in a PowerPoint presentation. After the stimulus was shown, participants described what happened. They could watch a clip again, but less than $5 \%$ of participants asked to do so.

Coding. Answers were classified according to the semantic characteristics of the main verb. This classification yielded five different categories of response: manner verbs, path verbs, neutral verbs, other events, and other answers. Neutral verbs are defined as forms that express motion without specifying path or manner (e.g. 'to go' or 'to move', Slobin, 1996b). Other events were lexical items that expressed other actions or events different from path, manner, or neutral verbs. These could be static descriptions like she is under a table, or a description unrelated to path or manner like he opened the door. Other answers 
refer to cases that were not purely manner or path verb sentences. They included sentences that contained two verb phrases (a path verb and a manner verb) and phrases without verbs.

\section{Results}

We first present the results from the linguistic task (experiment 2), followed by results from the non-verbal task (experiment 1) because the linguistic data set the scene for the cognitive data.

\section{Experiment 2: Verbal encoding of motion events}

Responses were scored as the number of times a child selected a manner verb, a path verb, a neutral verb, other events or other answer. Scores were converted into percentages and the mean was calculated for each language and age group (see Table 4).

Table 4. Means (and standard deviations) of type of verbs produced by children according to language and age (in percentages)

\begin{tabular}{|c|c|c|c|c|c|c|}
\hline & & $\begin{array}{l}\text { Manner } \\
\text { Verb } \\
\% \quad(\mathrm{SD})\end{array}$ & $\begin{array}{l}\text { Path Verb } \\
\%\end{array}$ & $\begin{array}{l}\text { Neutral Verb } \\
\% \quad(\mathrm{SD})\end{array}$ & $\begin{array}{l}\text { Other Events } \\
\% \quad(\mathrm{SD})\end{array}$ & $\begin{array}{l}\text { Other } \\
\text { Answer } \\
\% \quad(\mathrm{SD})\end{array}$ \\
\hline $\begin{array}{l}\text { English } \\
\text { monol. }\end{array}$ & $\begin{array}{l}\text { AG } 1 \\
\text { AG } 2\end{array}$ & $\begin{array}{l}92(12) \\
96(8)\end{array}$ & $\begin{array}{ll}1 & (3) \\
0 & (0)\end{array}$ & $\begin{array}{ll}6 & (11) \\
2 & (6)\end{array}$ & \begin{tabular}{|ll}
1 & $(3)$ \\
2 & $(6)$
\end{tabular} & $\begin{array}{ll}1 & (3) \\
0 & (0)\end{array}$ \\
\hline $\begin{array}{l}\text { Spanish } \\
\text { monol. }\end{array}$ & $\begin{array}{l}\text { AG } 1 \\
\text { AG } 2\end{array}$ & $\begin{array}{l}76(21) \\
64(21)\end{array}$ & $\begin{array}{l}13(18) \\
26(19)\end{array}$ & $\begin{array}{ll}3 & (6) \\
2 & (5)\end{array}$ & $\begin{array}{l}6(10) \\
7(10)\end{array}$ & $\begin{array}{l}2(5) \\
1(3)\end{array}$ \\
\hline Bilinguals & $\begin{array}{l}\text { AG } 1 \\
\text { AG } 2 \\
\end{array}$ & \begin{tabular}{|l|}
$55(28)$ \\
$79(12)$ \\
\end{tabular} & \begin{tabular}{|ll}
33 & $(31)$ \\
11 & $(11)$ \\
\end{tabular} & \begin{tabular}{|l|}
$10(7)$ \\
$4(9)$ \\
\end{tabular} & \begin{tabular}{|ll}
0 & $(0)$ \\
0 & $(0)$ \\
\end{tabular} & $\begin{array}{l}2(6) \\
1(5) \\
\end{array}$ \\
\hline
\end{tabular}

Because of the large number of empty cells in the categories neutral verb, other events, and other answer, we carried out statistical analyses only with the manner and path verb categories as dependent variables. 


\section{Cross-linguistic comparisons within each age-group}

Two One-Way ANOVAs for manner verb and path verb responses comparing all language groups in AG1 produced significant results. Brown-Forsythe tests ${ }^{2}$ yielded $F(11.041,45)=7.086, \mathrm{p}<.05$ for manner verbs and $F(7.562,45)=5.397, \mathrm{p}<.05$ for path verbs. Post-hoc tests showed that English speakers used significantly more manner verbs than Spanish speakers and bilinguals in their sentences $(\mathrm{p}<.05$ and $\mathrm{p}<.05$ respectively), while Spanish monolinguals and S-E bilinguals did not differ significantly from each other. Post-hoc tests showed that English monolinguals produced significantly fewer path verb responses than the other language groups $(\mathrm{p}<.05$ and $\mathrm{p}<.05$ respectively). Spanish monolinguals and S-E bilinguals did not differ significantly from each other.

Similar comparisons of all language groups within AG2 yielded significant differences. Brown-Forsythe test for manner verbs yielded $F(31.128,44)=20.963, \mathrm{p}<.05$. Post-hoc tests showed that the English group produced significantly more manner verbs than Spanish monolinguals and bilinguals did $(\mathrm{p}<.05$ and $\mathrm{p}<.05$ respectively). Furthermore, bilinguals produced significantly more manner verbs in their L1 than the Spanish group, $(\mathrm{p}<.05)$. Due to zero variance among English monolinguals for path verb selection, we could only report independent sample t-tests comparing Spanish monolinguals and S-E bilinguals. These tests showed that bilingual AG2 produced significantly less path verbs than Spanish AG2, $t(26)=2.111 \mathrm{p}<.05$.

The results showed that cross-linguistic differences between Spanish and English speakers were already apparent at AG1, while no L2 influence was observed in the bilingual group. At AG2, however, the bilinguals produced significantly more manner verbs and significantly fewer path verbs than their Spanish monolingual peers, thus 
displaying Spanish L1 verbal behaviour toward the direction of that of English monolingual children.

We observed developmental changes within language groups that seem to indicate that younger children are still in the process of acquiring the adult pattern of their languages. Spanish speakers increased their production of path verbs $(\mathrm{t}(35)=-1.963 \mathrm{p}<.05$, one-tailed) and decreased their use of manner verbs overall between AG1 and AG2 (t(35)=1.666 $\mathrm{p}<.05$, one-tailed). Bilingual groups, on the other hand, increased their production of manner verbs from AG1 to AG2 $(\mathrm{t}(6.002)=1.889 \mathrm{p}<.05$, one-tailed). The production of path verbs decreased but it did not show significant levels $(p=.08)$. On the other hand, English speakers from AG 1 and from AG2 did not differ in their preferences for path or manner.

\section{Effects of boundary-crossing and trajectory paths in Spanish monolinguals and S-E}

\section{bilinguals}

We analysed whether Spanish speakers and bilinguals differed in their production of manner and path verbs according to type of path, i.e. boundary-crossing and trajectory (see Figures 2 and 3). Paired samples t-tests confirmed that Spanish AG1 and AG2 produced significantly more manner verbs with trajectory paths than with boundary-crossing paths, $t(18)=11.696 \mathrm{p}<.05$ for $\mathrm{AG} 1$, and $t(17)=4.932 \mathrm{p}<0.05$ for $\mathrm{AG} 2$, while they produced more path verbs with boundary-crossing 4.745, p<.05 in AG2. These results confirm Slobin's hypothesis concerning Spanish description of motion events.

The Spanish-speaking group showed some developmental changes. AG2 children used significantly fewer manner verbs for boundary-crossing path than children from AG1 $(\mathrm{t}(33.40)=-1.704, \mathrm{p}<.05$, one-tailed, $)$; and the opposite picture is observed in relation to 
the use of path verbs which increased from AG1 to AG2 in relation to boundary-crossing paths $(\mathrm{t}(35)=2.722 \mathrm{p}<.05)$. The verbalization pattern observed in AG2 Spanish-speaking children looks similar to the adult pattern (i.e. preference for path verbs).

2a. Boundary-crossing path

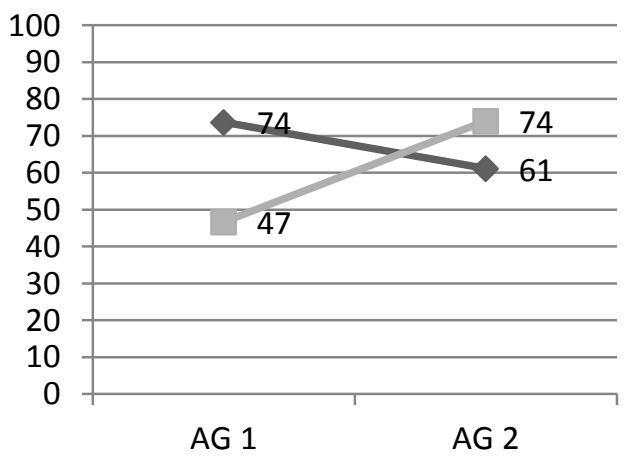

2b. Trajectory path

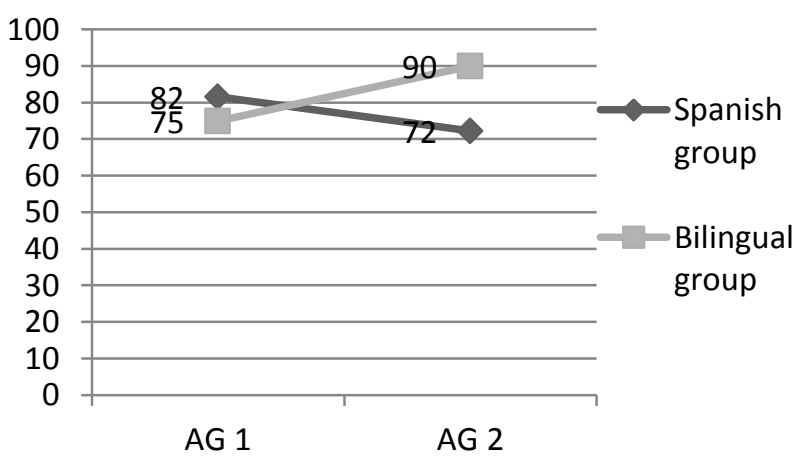

Figure 2a and $\mathbf{2 b}$. Manner verb responses in boundary-crossing paths and in trajectory paths in Spanish monolinguals and bilinguals, in percentages (rounded to the nearest whole number)

3a. Boundary-crossing path

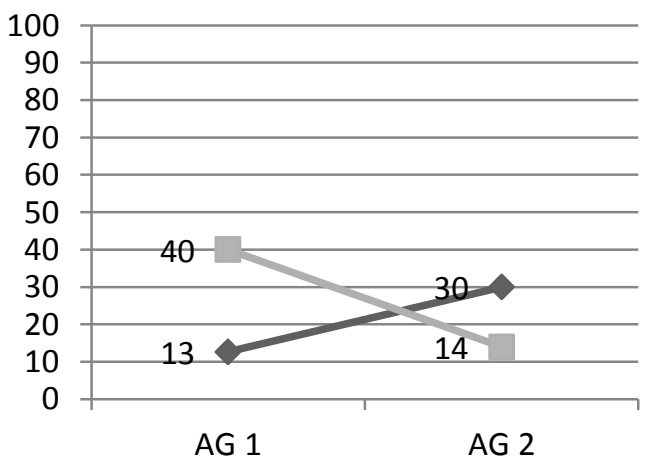

3b. Trajectory

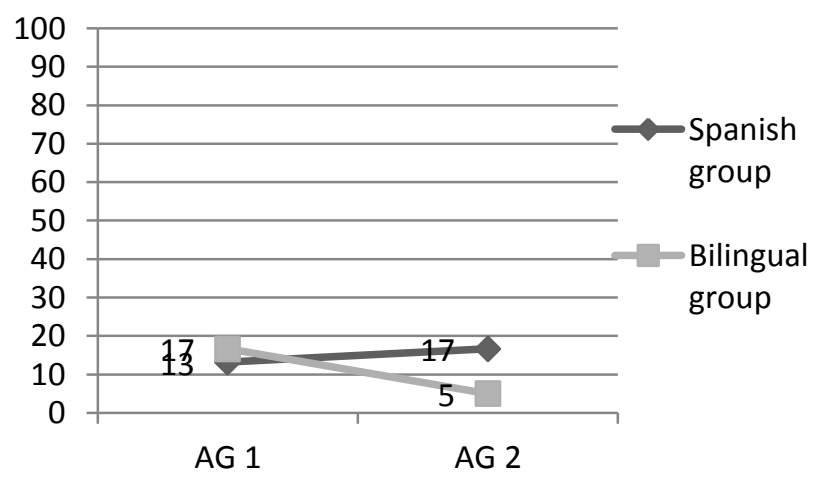

Figure 3a and 3b Path verb responses in boundary-crossing paths and trajectory paths in Spanish monolinguals and bilinguals, in percentages

AG2 bilinguals used more manner verbs with trajectory-paths than with boundarycrossing -paths, $t(9)=6.042, \mathrm{p}<.05$. AG1 bilinguals produced significantly more path verbs 
with boundary-crossing paths than with trajectory-paths, $t(5)=2.076 \mathrm{p}<.05$, similar to Spanish monolinguals. The same preference was observed in $A G 2, t(9)=2.714 \mathrm{p}<.05$. Additionally, AG2 bilinguals used significantly more manner verbs for boundary-crossing paths than AG1 bilinguals, $t(14)=-2372, \mathrm{p}<.05$ (see figures $2 \mathrm{a}-2 \mathrm{~b}$ ).

When Spanish monolingual and bilingual encodings were compared for the different types of path, AG1 Spanish speakers produced significantly more manner verbs than bilinguals in boundary-crossing paths $(\mathrm{t}(23)=2.437 \mathrm{p}<.05)$. AG1 bilinguals produced more path verbs in boundary-crossing path at near significance $(\mathrm{t}(5.555)=-1.632, \mathrm{p}=.07$, onetailed). AG2 bilinguals, on the other hand, produced significantly more manner verbs in boundary-crossing than AG2 Spanish speakers $(\mathrm{t}(24.950)=-1.791 \mathrm{p}<.05$, one-tailed) and nearly differed significantly in trajectory paths from the Spanish speakers $(\mathrm{t}(25.763)=1.669$ $\mathrm{p}=.054$, one-tailed). AG2 Spanish speakers on the other hand produced more path verbs than bilinguals in boundary-crossing paths $(\mathrm{t}(26)=2.385 \mathrm{p}<.05)$.

Finally, we analysed how path and manner components were expressed in the sentences. Table 5 shows the mean percentages of production of path verbs in combination with other path and manner components. Additionally, the same distribution is presented for manner verbs. Only path verbs and only manner verbs refer to the cases in which the verb only expresses a manner or a path component (i.e. a man is jumping).

AG1 Spanish-speaking children overwhelmingly preferred to use only path verbs $(79 \%)$ than any other combination. The typical adult pattern of path + manner is only used in $16 \%$ of total cases. This usage pattern, however, becomes higher (35\%) in AG2 children. In relation to manner verbs, the patterns are pretty similar in both age groups. Bilinguals showed a different tendency (see Table 5). The pattern of path+manner decreased between AG1 and AG2 bilinguals, which could indicate that these speakers are diverting from the 
adult pattern of their L1, under the influence of their L2. English AG1 produced a substantial proportion of only manner verbs (56\%), while the manner+path pattern (i.e. the typical English adult pattern reported in Talmy (1985) and Slobin (1996b) occurred in 34\% of total cases. This could indicate that in AG1, English speakers are not paying the same attention to path and manner, but that they may be paying more attention to manner. However, AG2 English speakers produced many more manner + path expressions (67\%). These patterns suggest that the youngest children from both monolingual groups are not following the adult pattern of path and manner of motion. However, from 7;00 years onwards the adult pattern of lexicalisation of motion events begins to emerge. Bilinguals performed differently from monolinguals in Spanish with respect to the verbalisation of path verbs and other path and manner components. AG2 bilinguals substantially used less path + manner patterns than AG1 bilingual and Spanish monolinguals in general. Table 6 presents the verbs elicited by the children.

Table 5. Distribution of path and manner components in the sentences produced by speakers (in percentages)

\begin{tabular}{|l|r|r|r|r|r|r|}
\hline & \multicolumn{2}{|c|}{ Spanish speakers } & \multicolumn{2}{c|}{ Bilinguals } & \multicolumn{2}{c|}{ English speakers } \\
\hline & \multicolumn{1}{|c|}{ AG1 } & \multicolumn{1}{c|}{ AG2 } & \multicolumn{1}{c|}{ AG1 } & \multicolumn{1}{c|}{ AG2 } & \multicolumn{1}{c|}{ AG1 } & \multicolumn{1}{c|}{ AG2 } \\
\hline & \multicolumn{1}{c|}{$\%$} & \multicolumn{1}{c}{$\%$} & \multicolumn{1}{c|}{$\%$} & \multicolumn{1}{c|}{$\%$} \\
\hline Path verbs & & & & & & 0 \\
\hline Only path verb & 79 & 65 & 53 & 80 & 100 & 0 \\
\hline Path + Manner & 16 & 35 & 47 & 10 & 0 & 0 \\
\hline Path + Path +Manner & 5 & 0 & 0 & 0 & 0 & 0 \\
\hline Path + Manner + Manner & 0 & 0 & 0 & 10 & 0 & 0 \\
\hline Total & 100 & 100 & 100 & 100 & 100 & 0 \\
\hline Manner verbs & & & & & & 0 \\
\hline Only manner verb & 86 & 72 & 66 & 79 & 56 & 32 \\
\hline Manner+ Path & 6 & 0 & 10 & 0 & 34 & 67 \\
\hline Manner + Manner + Path & 1 & 0 & 0 & 2 & 0 & 0 \\
\hline Manner + Path + Path & 0 & 0 & 0 & 0 & 0 & 0 \\
\hline Manner + Manner & 6 & 28 & 24 & 19 & 10 & 1 \\
\hline
\end{tabular}




\begin{tabular}{|l|r|r|r|r|r|r|}
\hline Total & 100 & 100 & 100 & 100 & 100 & 100 \\
\hline
\end{tabular}

Table 6. Verbs elicited by participants

\begin{tabular}{|l|r|l|r|r|}
\hline \multicolumn{2}{|c|}{$\begin{array}{c}\text { Verb elicited by English } \\
\text { speakers }\end{array}$} & $\begin{array}{c}\text { Verb elicited in } \\
\text { Spanish }\end{array}$ & $\begin{array}{r}\text { Spanish } \\
\text { speakers }\end{array}$ & Bilinguals \\
\hline be & 1 & arrastrarse/drag & 3 & 1 \\
\hline come & 1 & bailar/dance & 3 & 1 \\
\hline crawl & 35 & brincar/hop & 1 & 1 \\
\hline gallop & 1 & caminar/walk & 34 & 18 \\
\hline get & 2 & correr/run & 26 & 10 \\
\hline go & 9 & dar vueltas/turn & 21 & 7 \\
\hline hop & 24 & devolverse/return & 1 & 0 \\
\hline jog & 24 & entrar/enter & 25 & 7 \\
\hline jump & 31 & estar/be & 1 & 0 \\
\hline roll & 1 & gatear/crawl & 15 & 9 \\
\hline run & 18 & girar/twirl & 13 & 0 \\
\hline skip & 38 & ir/go & 9 & 5 \\
\hline spin & 17 & irse/set off & 1 & 0 \\
\hline turn & 4 & meterse/get in & 1 & 0 \\
\hline twirl & 8 & pasar/pass & 6 & 3 \\
\hline twist & 1 & ponerse/ place & 2 & 0 \\
\hline walk & 46 & rodar/roll & 1 & 0 \\
\hline & & salir/leave & 15 & 9 \\
\hline & & saltar/jump & 54 & 29 \\
\hline & & trotar/jog & 23 & 6 \\
\hline
\end{tabular}

\section{Experiment 1: Similarity judgment task}

In this task, participant responses fell into two types: the selection of same-manner videos implied the non-selection of the same-path video. Therefore, our dependent variable was same-manner selection. Children's choices were scored as the number of times they selected a same-manner response. These scores were converted into percentages and the mean was calculated for each language group and age group. Table 5 shows these means. 
Table 5. Total percentage same-manner selection (and standard deviations) according to language and age

\begin{tabular}{|l|l|cc|}
\hline \multicolumn{2}{|l|}{} & \multicolumn{2}{l|}{$\begin{array}{l}\text { Same-manner } \\
\text { responses }\end{array}$} \\
& & $\%$ & $($ SD) \\
\hline & AG 1 & 61.51 & $(22.47)$ \\
English monol. & AG 2 & 54.15 & $(18.04)$ \\
\hline & AG 1 & 63.45 & $(25.11)$ \\
Spanish monol. & AG 2 & 59.77 & $(25.45)$ \\
\hline & AG 1 & 72.53 & $(27.55)$ \\
Bilinguals & AG 2 & 65.33 & $(20.24)$ \\
\hline
\end{tabular}

All participants demonstrated high similarities independently of language and age group. One-Way ANOVAs comparing the different language groups within each age group did not yield any statistically significant differences. Additionally, we analysed children's same manner choices split by type of path and participants behaved similarly.

Summarizing, the study shows that children categorized motion events in the same fashion independently of language and age. Secondly, English-speaking and Spanishspeaking children showed cross-linguistic differences in their verbal encoding of motion events toward the adult pattern of their languages. This difference was already apparent at AG1, and became more pronounced at AG2. Bilingual children at AG1 followed the lexicalisation patterns of their L1. However, AG2 bilinguals produced more manner verbs and less path verb + manner constructions than their Spanish monolingual peers, which suggests an L2 effect on L1 motion event encoding. 


\section{Discussion}

The current study investigated motion event encoding and non-verbal categorisation in monolingual Spanish and English children, and S-E bilinguals. We employed a verbal encoding task and a similarity judgment task, exploring effects of the L2 on L1 lexicalisation patterns (TFS), and effects of linguistic structure on non-verbal motion event categorisation (LR), respectively. Results from the verbal encoding task revealed the developmental trajectory of path and manner expression in these children in two key respects. Firstly, and consistent with previous literature (Papafragou \& Selimis, 2010; Papafragou et al., 2002), we found robust cross-linguistic differences between monolingual groups, already well established by age 5. Secondly, Spanish-English bilinguals displayed L1 lexicalisation patterns near chance levels at ages 5 and 6, but by age 7 their L1 lexicalisation patterns had shifted between those of monolingual children of either language, under the joint influence of the L1 and the L2. The likely cause of this shift is the increasing expertise in the L2, clearly reflected in the bilinguals' PPVT scores, which differed substantially between the two age groups. AG 2 bilinguals have the English knowledge of a monolingual English-speaking child of nearly 4;00 years old, as opposed to AG 1 bilinguals whose English knowledge reflected that of a monolingual Englishspeaking child younger than 2;06 years-old (see table 2).

Results from the similarity judgement task, however, showed no cross-linguistic differences. This dissociation of verbal and non-verbal behaviour is entirely consistent with the increasing observation in the field of language and cognition that differences between populations in TFS do not automatically entail LR differences (Gennari et al., 2002; 
Papafragou \& Selimis, 2010). Other studies (Malt \& Sloman, 2003; Ameel et al., 2005) show that whereas substantial cross-linguistic differences occur between populations in semantic categorisation of objects, no differences are found when the same populations are asked to freely sort the objects into categories: common perceptual attributes of objects override their semantic denotations for the purposes of non-linguistic categorisation. This dissociation of verbal and non-verbal processing in monolinguals and bilinguals has important ramifications for how linguistic and non-linguistic knowledge is represented in the mind. Specifically, in line with Lucy (1997), Malt and Sloman (2003) and others, the current study demonstrates that it is necessary to theoretically distinguish between a linguistic level of representation (which concerns phenomena related to selecting and structuring content for speech as captured by the TFS paradigm), and a non-linguistic conceptual level (which concerns cognitive representation of concepts that may be language-derived to a lesser or greater extent depending on the conceptual category, the task, etc., (cf. Athanasopoulos \& Bylund, 2013)).

The main finding of the current study is the influence of the L2 on L1 verbal encoding (TFS) patterns in child L2 learners. To date, the majority of studies in this domain have focused on adults (cf. Hohenstein et al., 2006; Brown \& Gullberg, 2010). The current study makes an important contribution to the existing investigations in adults, because it provides the first evidence of L2 effects on L1 motion event encoding in child L2 acquisition. In line with the findings in adults, it shows that such effects emerge well before L2 learners reach an advanced level of proficiency.

These results can be explained by Ameel et al.'s (2005) theory of lexico-semantic representations in early bilinguals, which posits that these speakers converge towards a common naming pattern. Ameel et al. (2005) asked adult balanced simultaneous bilinguals 
of Dutch and French to name and then freely categorise 73 photographs of storage containers (such as bottles and jars) and 67 photographs of cups and dishes. Their naming and non-verbal categorisation behaviour was compared to monolingual speakers of Dutch and French. The results showed that while the monolinguals displayed language-specific naming patterns with different semantic category boundaries for the different classes of objects, the bilinguals converged towards a common naming pattern, suggesting merged lexico-semantic representations sharing elements from both languages. The researchers concluded that "through the mutual influence of the languages, the category boundaries in the two languages move towards one another and hence diverge from the boundaries drawn by the native speakers" (2005: 79). Our study supports this theory as far as L2 influence on the L1 is concerned, and provides converging evidence from child L2 learners to show that this mutual influence from the two languages of the bilingual can extend beyond the single word level and static objects to the lexical semantics of verbs used to describe dynamic motion events.

The study's secondary aim was to test whether Spanish speakers produced more manner verbs when the event showed a trajectory, rather than a boundary-crossing path, and more path verbs with boundary-crossing paths than with trajectory paths. This hypothesis is fully supported for Spanish monolingual children. Bilinguals were similar to Spanish speakers in that they showed a significant preference for path verbs with boundary-crossing paths than trajectory-paths at both age groups. However, the performance of manner verb selection diverged from that of Spanish monolinguals. In the younger age group there was no difference in the use of manner verbs across the two types of path. In the older age group manner verb responses increased significantly for boundary-crossing paths. Thus, even though overall their L1 has been influenced by their L2, they still display core L1 
characteristics in their lexicalisation of different types of paths, but only when they produce path verbs (a linguistic feature that is more prominent in their L1 than in their L2).

Bilinguals' use of manner verbs, which is the prominent linguistic feature in their L2, diverged from Spanish monolinguals, presumably under the influence of English, whose speakers tend to produce manner verbs when describing motion events.

The current study opens up several new avenues for investigation. Our study did not show any differences in children in the non-verbal similarity judgement task, but it is possible that in different paradigms, and/or in older children, such differences may still be observed. Specifically, in the domain of motion, linguistic influence on cognition depends on the degree to which language is used explicitly in the task. Such instances include experimental manipulations where participants have verbalised stimuli immediately prior to categorising them (Gennari et al., 2002), when instructions contain linguistic cues priming participants to respond in language-specific ways (Papafragou \& Selimis, 2010), when stimuli are presented in a recognition paradigm (Filipovic, 2011), or in a training context (Kersten et al., 2010), both of which involve utilisation of linguistically-mediated long term and working memory to accomplish the task. In addition, given that the motion event linguistic system fully matures relatively late in development, it could be years before LR effects become observable (cf. Lucy \& Gaskins, 2001). An interesting extension of the current study would be to investigate the performance of monolingual and bilingual children in linguistically mediated cognitive paradigms of the type described above, and include older children and adolescents, as these groups may exhibit differences in nonverbal behaviour due to their increased experience with their native (and in the case of bilinguals, their second) language. 
Secondly, the study focused on whether L1 lexicalisation patterns can be restructured under the influence of the L2. We have, therefore, left open the question of the extent of L1 influence on L2 production, since we did not gather such data.

\section{Conclusion}

The study directly looked at the L1 performance of child L2 learners within the TFS framework. It revealed that bilinguals develop L1 motion encoding patterns that merge those of their specific languages. As a result of this merging process, L1 lexical concepts in bilingual children differ from those of monolingual children of their L1, and move toward those of monolingual children of their L2. At the same time, the bilinguals' L1 motion event encoding does not completely approximate that of monolingual speakers of the L2. This 'in-between' pattern of motion lexicalisation leads us to conclude that acquiring an L2 early in life affects the development of lexical concepts in the L1. This 'in-between' pattern of verbal behaviour also supports previous theories of bilingual semantic representation that postulated a merged lexico-semantic system in early bilinguals (Ameel et al., 2005), and for

the first time establishes that this merged system emerges in children from intermediate stages of L2 proficiency. The study observed no LR effects, so we leave open the possibility that effects of language on motion event cognition may be observed later in development, and by utilizing paradigms that promote explicit or implicit use of language, consistent with studies on adult cognitive behaviour in this domain.

\section{Notes}


1 The terms S-E bilinguals and bilinguals are used indistinctively in this article. The terms monolingual English-speaking children, English monolinguals, English group are also used indistinctively. The same terms apply to monolingual Spanishspeaking children.

2 Because of the non-homogeneous nature of our data, and due to the extreme means observed, we report the Brown-Forsythe statistical values for each ANOVA test (Field, 2005).

\section{Acknowledgments}

We wish to thank the special issue editors and 3 anonymous reviewers for constructive feedback. We are grateful to Prof. Ginny Gathercole for methodological advice, and Petar Simonovic for proof-reading an earlier version of the manuscript. 


\section{References}

Ameel, E., Storms, G., Malt, B.C., \& Sloman, S. A. (2005). How bilinguals solve the naming problem. Journal of Memory and Language, 53, 60-80.

Aske, J. (1989) Path predicates in English and Spanish: a closer look. Proceedings of the Fifteenth Annual Meeting of the Berkeley Linguistic Society. 1-14. Berkeley, CA: Berkeley Linguistics Society.

Athanasopoulos, P. \& Bylund, E. (2013). Does grammatical aspect affect motion event cognition? A cross-linguistic comparison of English and Swedish speakers. Cognitive Science, 37, 286-309.

Athanasopoulos, P. (2006). Effects of the grammatical representation of number on cognition in bilinguals. Bilingualism: Language and Cognition, 9, 89-96.

Athanasopoulos. P. , \& Kasai, C. (2008). Language and thought in bilinguals: The case of grammatical number and nonverbal classification preferences. Applied Psycholinguistics, 29, 105-123.

Aveledo, F. (2014). Linguistic relativity in motion events in Spanish and English: a study on monolingual and bilingual children and adults. Unpublished PhD Dissertation:

Newcastle University.

Boroditsky, L. (2001). Does language shape thought? English and Mandarin speakers'conceptions of time. Cognitive Psychology, 43, 1-22.

Boroditsky, L., Schmidt, L., \& Phillips, W. (2003). Sex, syntax, and semantics. In D. Gentner, \& S. Goldin-Meadow (Eds.), Language in mind: Advances in the study of language and cognition (pp. 61-80). Cambridge, MA: MIT Press.

Brown, A., \& Gullberg, M. (2010). Changes in encoding of PATH of motion in a first language during acquisition of a second language. Cognitive Linguistics, 21, 263-286.

Bylund, E. (2009). Effects of age of L2 acquisition on L1 event conceptualisation patterns. Bilingualism: Language and Cognition, 12, 305-322. 
Bylund, E., \& Jarvis, S. (2011). L2 effects on L1 event conceptualisation. Bilingualism: Language and Cognition, 14, 47-59.

Choi, S., \& Bowerman, M. (1991). Learning to express motion events in English and Korean: The influence of language-specific lexicalisation patterns. Cognition, 41, 83-121.

Dunn, L., \& Dunn, L. (1981). Peabody picture vocabulary test-revised. Toronto, Canada: Psycam.

Field, A. (2005). Discovering statistics using SPSS. London, UK: SAGE Publications.

Feist, M., Rojo, A., \& Cifuentes, P. (2007) Salience and acceptability in Spanish manner verbs: A preliminary view. International Journal of English Studies, 7, 137-148.

Filipovic, L. (2011). Speaking and remembering in one or two languages: bilingual vs. monolingual lexicalisation and memory for motion events. International Journal of Bilingualism, 15, 466-485.

Gennari S., Sloman S.A., Malt, B. C., \& Fitch, W. T. (2002). Motion events in language and cognition. Cognition, 83, 49-79.

Grosjean, F. (2001). The bilingual's language modes. In J.L. Nicol (Ed.), One mind, two languages: Bilingual language processing (pp. 1-22). Oxford: Blackwell.

Hohenstein, J. (2005). Language-related motion event similarities in Spanish- and Englishspeaking children. Journal of Cognition and Development, 6, 402-425.

Hohenstein, J., Eisenberg, A., \& Naigles, L. (2006). Is he floating across or crossing a float? Cross-influence of L1 and L2 in Spanish-English bilingual adults. Bilingualism: Language and Cognition,9, 249-261.

Kersten, A., Meissner, C., Lechuga, J., Schwartz, B. , Albrechtsen, J., \& Iglesias, A. (2010). English speakers attend more strongly than Spanish speakers to manner of motion when classifying novel objects and events. Journal of Experimental Psychology: General, $139,638-653$.

Lucy, J.A. (1997). Linguistic relativity. Annual Review of Anthropology, 26, 291-312.

Lucy, J. A., \& Gaskins, S. (2001). Grammatical categories and the development of classification preferences: A comparative approach. In M. Bowerman \& S. Levinson (Eds.), Language acquisition and conceptual development (pp. 257-283). New York, NY: Cambridge University Press.

Malt, B. C., \& Sloman, S. A. (2003). Linguistic diversity and object naming by non-native speakers of English. Bilingualism: Language and Cognition, 6, 47-67. 
Nagy Z., Westerberg H., Klingberg T. (2004). Maturation of white matter is associated with the development of cognitive functions during childhood. Journal of Cognitive

Neuroscience, 16, 1227-1233.

Naigles, L. , Eisenberg, A. , Kako, E. , Highter, M. , \& McGraw, N. (1998). Speaking of motion: Verb use in English and Spanish. Language and Cognitive Processes, 13, 521-549.

Papafragou, A., Massey, C., \& Gleitman, L. (2002). Shake, rattle, 'n' roll: The representation of motion in language and cognition. Cognition, 84, 189-219.

Papafragou, A., \& Selimis, S. (2010) Event categorisation and language: A cross-linguistic study of motion. Language and Cognitive Processes, 25, 224-260.

Regier, T., \& Kay, P. (2009). Language, thought, and color: Whorf was half right. Trends in Cognitive Sciences, 13, 439-446.

Sebastián, E., \& Slobin, D. (1994). The development of linguistic forms: Spanish. In R. Berman, \& D. Slobin (Eds.), Relating events in narrative (pp. 239-284). Hillsdale, NJ: Lawrence Erlbaum.

Slobin, D. (1987) .Thinking for Speaking. Proceedings of the Thirteenth Annual Meeting of the Berkeley Linguistic Society. 335-34

Slobin, D. (1996a). From "thought and language" to "thinking for speaking." In J. J. Gumperz, \& S. C. Levinson (Eds.), Rethinking linguistic relativity (pp. 70-96). New York, NY: Cambridge University Press.

Slobin, D. (1996b). Two ways to travel: Verbs of motion in English and Spanish. In M. Shibatani, \& S. A. Thompson (Eds.), Grammatical constructions: Their form and meaning (pp. 195-217). Oxford, UK: Oxford University Press.

Slobin, D., \& Hoiting, N. (1994). Reference to movement in spoken and signed languages: Typological considerations. Proceedings of the Twentieth Annual Meeting of the Berkeley Linguistics Society: General Session Dedicated to the Contributions of Charles J. Fillmore, 487-505.

Talmy, L. (1985). Lexicalisation patterns: Semantic structure in lexical forms. In T. Shopen (Ed.), Grammatical categories and the lexicon. Language typology and syntactic description (pp. 57-149). Cambridge, MA: Cambridge University Press.

Whorf, B. (1956). Language, thought, and reality. Cambridge, MA: MIT Press.

Wolff, P., \& Holmes, K. J. (2010). Linguistic relativity. Wiley Interdisciplinary Reviews: Cognitive Science, 2, 253-265. 
